
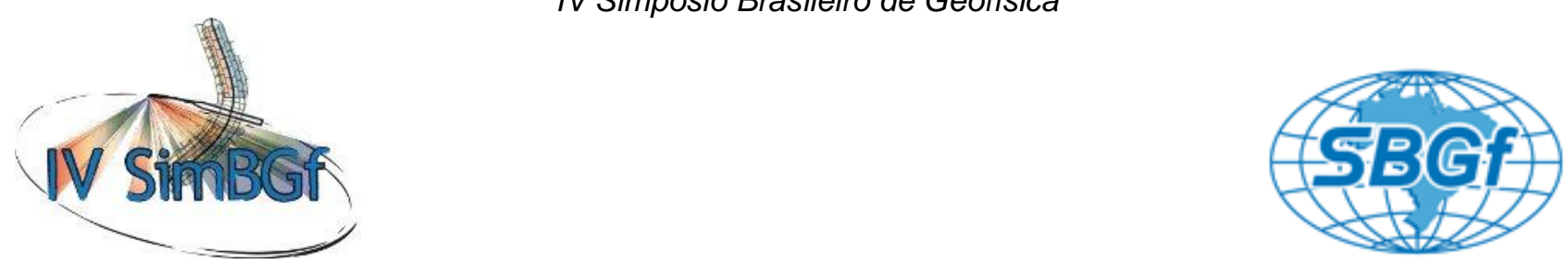

\title{
Interpretação conjunta de sismicidade desencadeada por reservatório, e magnetometria - Irapé-MG
}

\author{
Braga A.A. ${ }^{1}$, Von Huelsen M.G. ${ }^{2}$, Chimpliganond, C.N. ${ }^{3}$, Matos D.R. ${ }^{4}$ \\ ${ }^{1}$ Instituto de Geociências da Universidade de Brasília. Contato: artur.areal.braga@gmail.com \\ ${ }^{2}$ Instituto de Geociências da Universidade de Brasília. Contato: monisis@unb.br \\ 3 Instituto de Geociências da Universidade de Brasília. Contato: naibert@unb.br \\ ${ }^{4}$ Instituto de Geociências da Universidade de Brasília. Contato: deb.rmatos@gmail.com
}

Copyright 2010, SBGf - Sociedade Brasileira de Geofísica

Este texto foi preparado para a apresentação no IV Simpósio Brasileiro de Geofísica, Brasília, 14 a 17 de novembro de 2010. Seu conteúdo foi revisado pelo Comitê Técnico do IV SimBGf, mas não necessariamente representa a opinião da SBGf ou de seus associados. É proibida a reprodução total ou parcial deste material para propósitos comerciais sem prévia autorização da SBGf.

\section{RESUMO}

A Região da UHE de Irapé-MG está localizada na fronteira entre a parte central da província São Francisco e a província mantiqueira, no noroeste do estado de Minas Gerais. Estudos vêm sendo feitos desde 2005, quando ocorreu a sismicidade na região de influência da barragem. Entre os anos de 2005 e 2007, período em que foram obtidos os dados desse estudo, houve o registro de 351 eventos sísmicos. Este trabalho tem por objetivo a interpretação conjunta da sísmica previamente estudada com métodos geofísicos (magnetometria). A partir do processamento dos dados geofísicos foram obtidos produtos, a fim de observar as diferentes especificidades da área, além da interpretação integrada.

\section{INTRODUÇÃO}

A usina de Irapé trabalha, cotidianamente, com potência instalada de $360 \mathrm{MW}$. A Cemig é empresa concessionária responsável pela construção e exploração da hidrelétrica. Sua barragem é a mais alta do Brasil e a segunda maior da América Latina, com 208 metros. Um estudo geofísico desta área é importante, pois desde 2005, logo após o enchimento da barragem, sua área de influência apresentou sismicidade. Foram então realizados estudos de magnetometria e sismologia com a devida integração destes dados.

\section{Localização e Geologia}

A área em estudo, de $1474 \mathrm{~km}^{2}$, foca os arredores da usina de Irapé, Hidrelétrica Presidente Juscelino Kubitscheck, que foi construída no rio Jequitinhonha, entre os municípios de Berilo e Grão Mogol, no nordeste do estado de Minas Gerais na Região Centro-Oeste do Brasil (Figuras 1). O reservatório de Irapé abrange os municípios de Grão Mogol, Cristátia, Botumirim, José Gonçalves de Minas, Berilo, Leme do Prado e Turmalina.

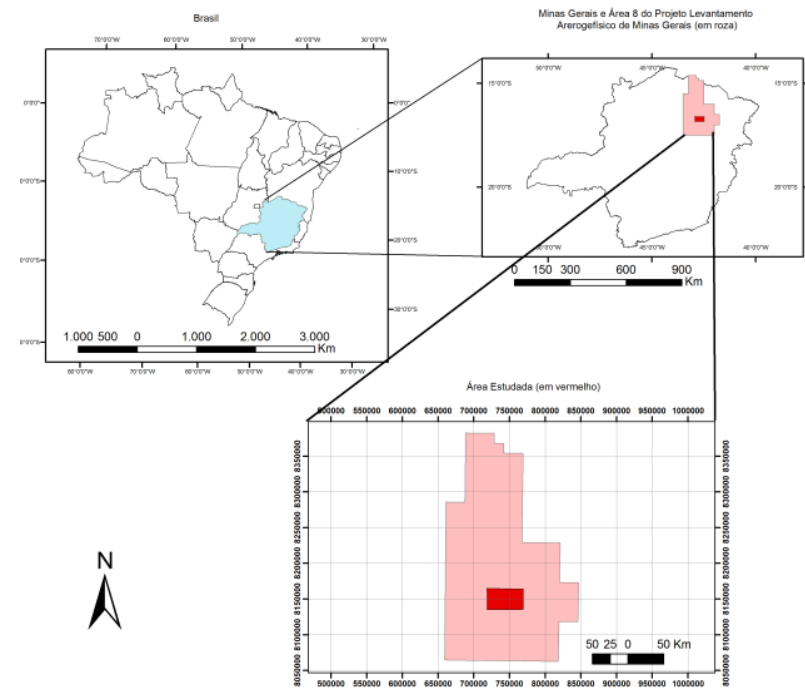

Figura 1- Localização da área estudada e do levantamento aerogeofísico.

Afloram na área investigada, rochas do Grupo Macaúbas, Formação Nova Aurora e Membro Rio Preto da Formação Chapada Acauã, e da Formação Salinas relacionadas ao Orogeno Araçuaí. Elas se formaram na bacia Macaúbas com o rifteamento do Cráton São Francisco-Congo durante o Neoproterzóico. As rochas referentes ao magmatismo do início da fase rift (906-875 $\mathrm{Ma})$, são diques máficos da Suíte Pedro Lessa e granitos anorogênicos da Suíte Salto da Divisa. Os xistos verdes basálticos do Membro Rio Preto da Formação Chapada Acauã, já no Grupo Macaúbas, são relacionados a um estágio mais tardio do magmatismo.

O Grupo Macaúbas possui uma idade de início de sedimentação de $900 \pm 21 \mathrm{Ma}$, referente à base das unidades, Formações Duas Barras e Rio Peixe Bravo, que são devido à sedimentação de margem continental passiva. 
INTERPRET. CONJ. SISMIC. D. POR RESERV., E MAG. - IRAPÉ-MG

As unidades glaciais depositadas durante a fase rifte do Orógeno são a Formação Serra do Catuni, com rochas que indicam a sedimentação glácio-terrestre a gláciomarinha, e é seguida pela Formação Nova Aurora, de sedimentação glacio-marinha, apresentando formações ferríferas diamictíticas. O Membro Mato Grande (Unidade Inferior) do Grupo Macaúbas é de sedimentação glaciomarinha distal, com característica transicional para o fim da glaciação.

Os Xistos verdes da Formação Chapada Acauã (Membro Rio Preto) estão intercalados em parte da pilha diamictítica. Seus protólitos são basaltos de vulcanismo na fase tardia do rifte Macaúbas, quando a crosta continental já se encontrava muito estirada.

Com a seqüência da abertura do rifte Macaúbas têm-se depositadas as pilhas de sedimentação pós-glacial em margem continental passiva, unidade superior da Formação Chapada Acauã (plataformal) e Formação Ribeirão da Folha (distal), onde ocorrem lascas ofiolíticas.

A Formação Salinas (marinha) mostra evidências marcantes de uma bacia que recebeu sedimentos provenientes do arco magmático do Orógeno Araçuaí. Este é representado pela Suíte G1 e pelas rochas vulcânicas do Grupo Rio Doce, ele foi edificado no estágio pré-colisional, possui a foliação regional, muitas vezes milonítica, e outras estruturas impressas pela deformação sin-colisional.

Existe um trabalho concomitante a este que realiza o mapeamento geológico-estrutural da mesma região e posteriormente haverá a integração destes dois.

\section{METODOLOGIA/PROBLEMA INVESTIGADO}

\section{Dados Geofísicos}

Os dados sismológicos foram cedidos pela CEMIG (Centrais Elétricas de Minas Gerais), os quais são objeto de contrato entre a própria CEMIG e o Observatório Sismológico de Brasília (SIS); os dados aerogeofísicos (magnetométricos) foram obtidos pela Codemig, Companhia de Desenvolvimento Econômico de Minas Gerais, em parceria com a CPRM, Serviço Geológico do Brasil, como parte do Projeto de Levantamento Aerogeofísico de Minas Gerais 2005/2006. A área estudada está localizada na Área 8 do projeto. Ela compreende parte da região norte do estado de Minas Gerais (Figura 1). O levantamento dos dados de magnetometria e gamaespectometria percorreu linhas de vôo e controle espaçadas de $0,5 \mathrm{~km}$ e $10,0 \mathrm{~km}$, respectivamente, orientadas nas direções N25W e N65E. A altura do vôo foi fixada em $100 \mathrm{~m}$ do solo.

\section{Processamento dos Dados Geofísicos}

Os dados de sismologia foram processados utilizando 0 progama Seismic Analysis Code - SAC (GOLDSTEIN and SNOKE, 2005). Os dados aerogeofísicos foram processados em ambiente Geosoft Oasis Montaj (versão 7.2) gerando os produtos que foram interpretados em ambiente Arcgis ArcMap (versão 9.3).

\section{Sismologia : Processamento e resultados}

O monitoramento local do reservatório começou em dezembro de 2003 e mostrou uma região sem sismos até o enchimento do reservatório. Estudos em sismologia mostraram que um dia após o enchimento do lago foram detectados os primeiros tremores (Chimpliganond et al., 2010). Uma rede local de quatro estações detectou cerca de 330 eventos até 2007 (Figura2). O maior evento ocorreu em 2006 com magnitude 3,0. A localização epicentral foi realizada utilizando o método do azimute reverso (Figura 3).

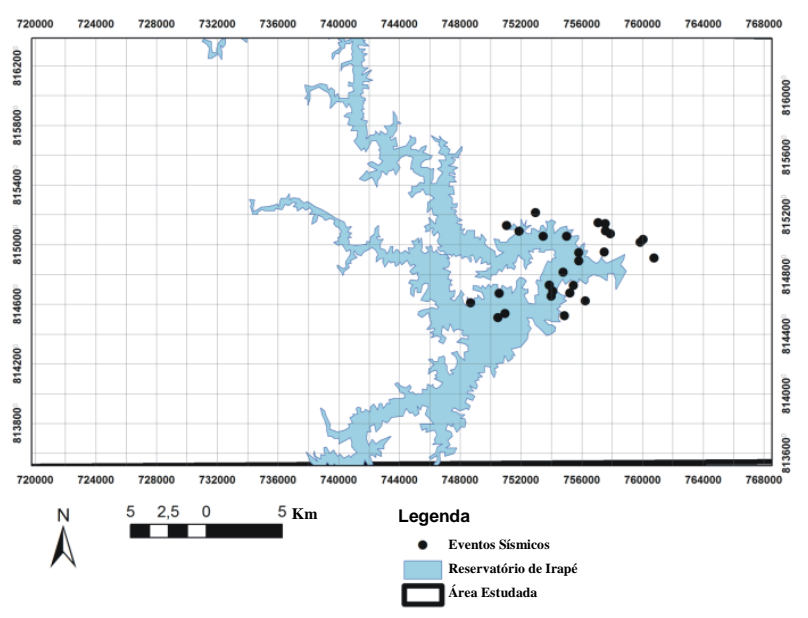

Figura 2 - Localização dos epicentros e reservatório.

\section{Magnetometria: Processamento e Resultados}

Os principais produtos, do processamento magnetométrico, realizados foram: Amplitude do Sinal Analítico (ASA), Derivada vertical (dZ), Inclinação do sinal Analítico (ISA), Amplitude do Gradiente Horizontal Total (AGHT), Fase Local do Sinal Analítico (FLSA) e a deconvolução de Euler. Além disso, foram geradas composições dos produtos acima tendo como destaque a composições ASA com ISA (Figura 4). Tais produtos auxiliaram na interpretação e na definição dos lineamentos magnéticos bem como nas localizações horizontal e vertical das fontes. Baseando-se nas diferentes intensidades do campo magnético bem como em suas estruturas definiu-se cinco domínios magnéticos (Figura 4). O D1 foi definido com a maior área entre os domínios. Aparentemente ele é limitado por duas falhas, uma a leste e uma a oeste. A falha a oeste é marcada por uma anomalia magnética positiva, linear e contínua 
Braga A.A, Von Huelsen M.G, Chimpliganond, C.N, Matos D.R.

com direção praticamente N-S. O D2 situa-se a oeste do $\mathrm{D} 1$, nele há três conjuntos de anomalias positivas, contínuas e lineares, de direções aproximadamente N-S, SE-NW e NNE-SSW. O D3 está presente em três regiões da área, ele apresenta uma baixa amplitude de sinal analítico e em uma de suas porções, aquela a SE da área, existe uma anomalia positiva linear e contínua com direção SW-NE

Os corpos magnéticos geométricos foram inseridos em domínios individuais, D4 para o corpo a NW da área e D5 para o corpo a SE. O corpo magnético D4 é aproximadamente circular (Figura 4, Domínio D4).

A Figura 6 mostra os lineamentos magnéticos interpretados e sobrepostos à imagem FLSA, bem como a localização dos epicentros dos eventos sísmicos. Pode-se notar que nesta região epicentral as direções dos lineamentos magnéticos encontram-se preferencialmente na direção NE-SW (Figura 5). Destacando-se essas duas áreas citadas acima, foram realizados processamento em $3 \mathrm{D}$ no intuito de modelar as regiões (Figuras 7 e 8 ).

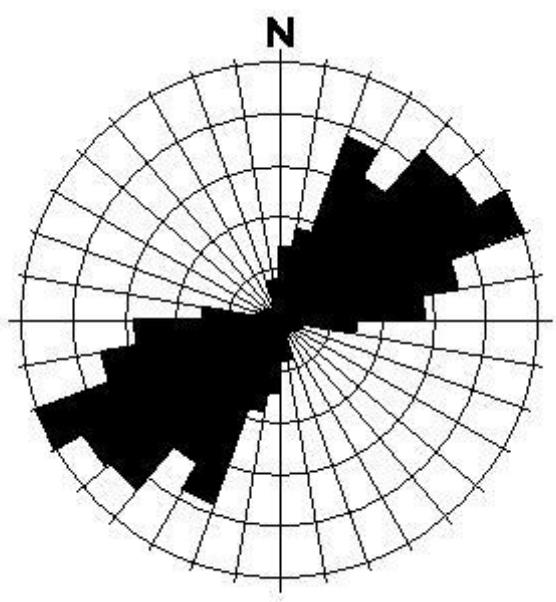

Figura 5 - Diagrama da distribuição dos lineamentos magnéticos. Com direções preferencialmente NE-SW.

\section{Discussão e Conclusões}

A sismicidade, provavelmente, desencadeada no reservatório de Irapé é considerada inicial ou de resposta rápida, ou seja, ocorre muito próxima ao reservatório e os eventos tiveram início logo após o enchimento do lago.

Este trabalho teve por objetivo a interpretação conjunta dessa sísmica previamente estudada com métodos geofísicos, em especial a magnetometria, para dar uma interpretação geofísica para a área em que se encontra a totalidade dos prováveis eventos induzidos pela UHE de Irapé. A divisão da área em domínios magnéticos nos dá artifício suficiente para localizar algumas falhas estruturais. Os limites E e W do D1 são marcadores da variação do padrão de contraste magnético entre os domínios adjacentes. Essas variações, por serem tão fortes, podem ser evidências de falhas estruturais. Os epicentros se encontram neste domínio numa área que prevalece os lineamentos magnético com direção NE-SW e profundidades chegando a $2 \mathrm{~km}$ (Figura 7). O corpo magnético geométrico localizado no D4, que após a modelagem 3D foi possível visualizá-lo como um corpo cilíndrico e com o sinal cada vez mais magnético à medida que se aproxima de seu núcleo (Figura 8). Assim este trabalho vem contribuir para o melhor conhecimento das estruturas geológicas e suas propriedades geofísicas.

\section{Agradecimentos}

Agradecemos à CEMIG, a CPRM, ao Observatório Sismológico e ao Laboratório de Geofísica da Universidade de Brasília que tornaram possível este trabalho.

\section{Referências}

CARVALHO, L.M.M.. Integração de dados de geofísica aérea aplicada à geologia e à prospecção mineral no distrito esmeraldífero de itabira-ferros, Quadrilátero Ferrífero - MG. Brasília, IG-UnB, Tese de Doutorado.

Chimpliganond, C. N., G. S. França, A. Bandeira, and L. Bevilaqua (2007), Reservoir-triggered seismicity at the highest Brazilian dam, American Geophysical Union, Spring Meeting, Acapulco, Mexico.

Kearey, F., Brooks, M. \& Hill, I., 2002. An introduction to geophysical exploration. Blackwell Science Ltd, UK.

SANTOS R.F, ALKMIM F. F., PEDROSA-SOARES A. C. 2009. A Formação Salinas, Orógeno Araçuaí (MG): história deformacional e significado tectônico .Revista Brasileira de Geociências, 39(1): 81-100 .

PEDROSA-SOARES A.C., NOCE C.M., ALKMIM F. F., SILVA L.C., BABINSKI M., CORDANI U., CASTEÑEDA C. 2007. Orógeno Araçuaí evolução do Conhecimento 30 anos após Almeida 1977. Geonomos, 15 (1): 1-16. 


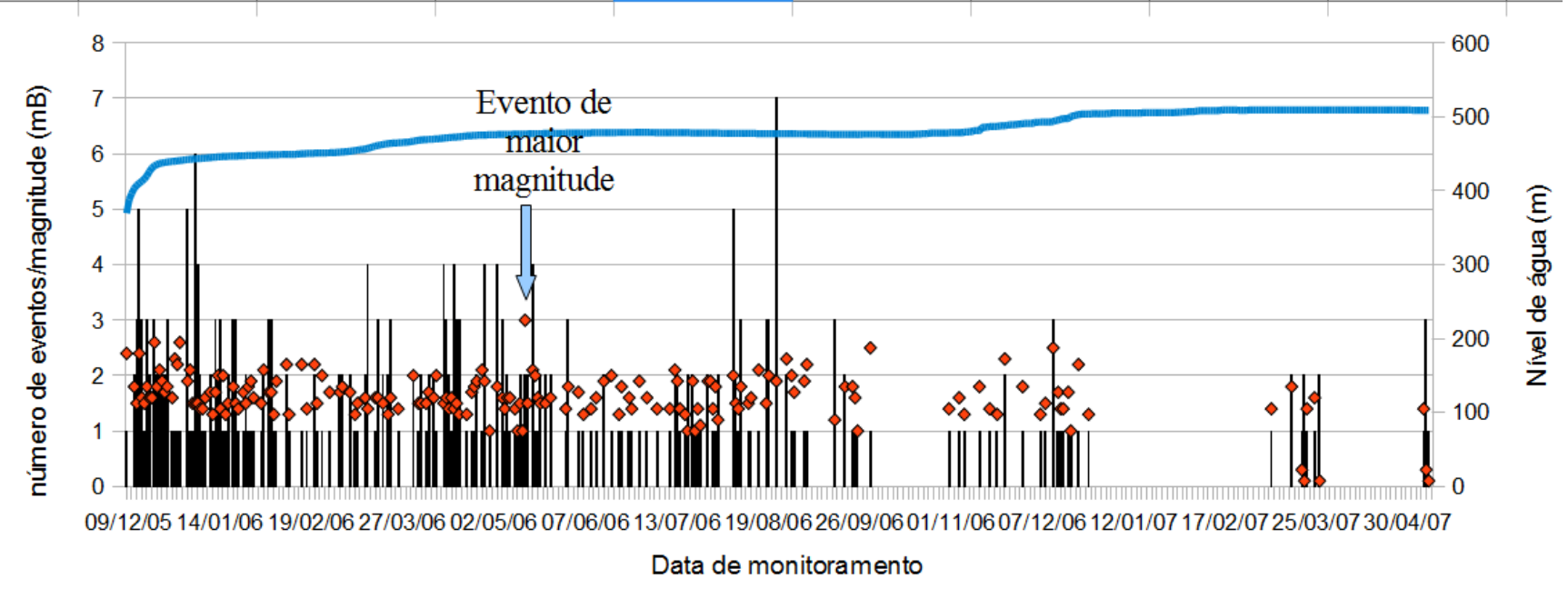

Figura 3 - Histograma mostrando o número de eventos pela data e o nível de água (linha azul).

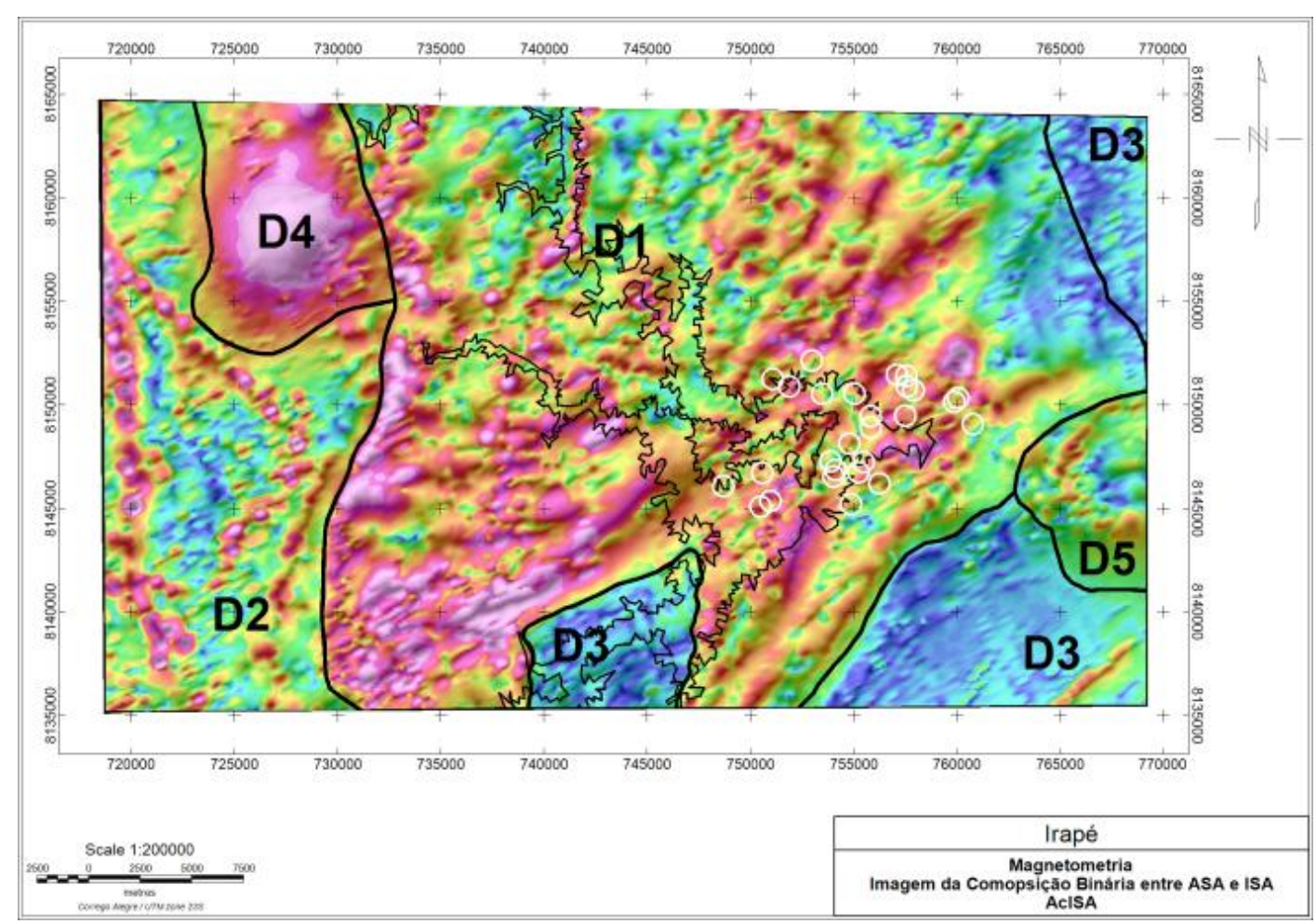

Figura 4 - Imagem da composição das imagens ASA e FLSA, a interpretação em domínios (D1, D2, D3, D4 e D5), contorno do reservatório de Irapé e os epicentros dos eventos sísmicos (círculos brancos). 


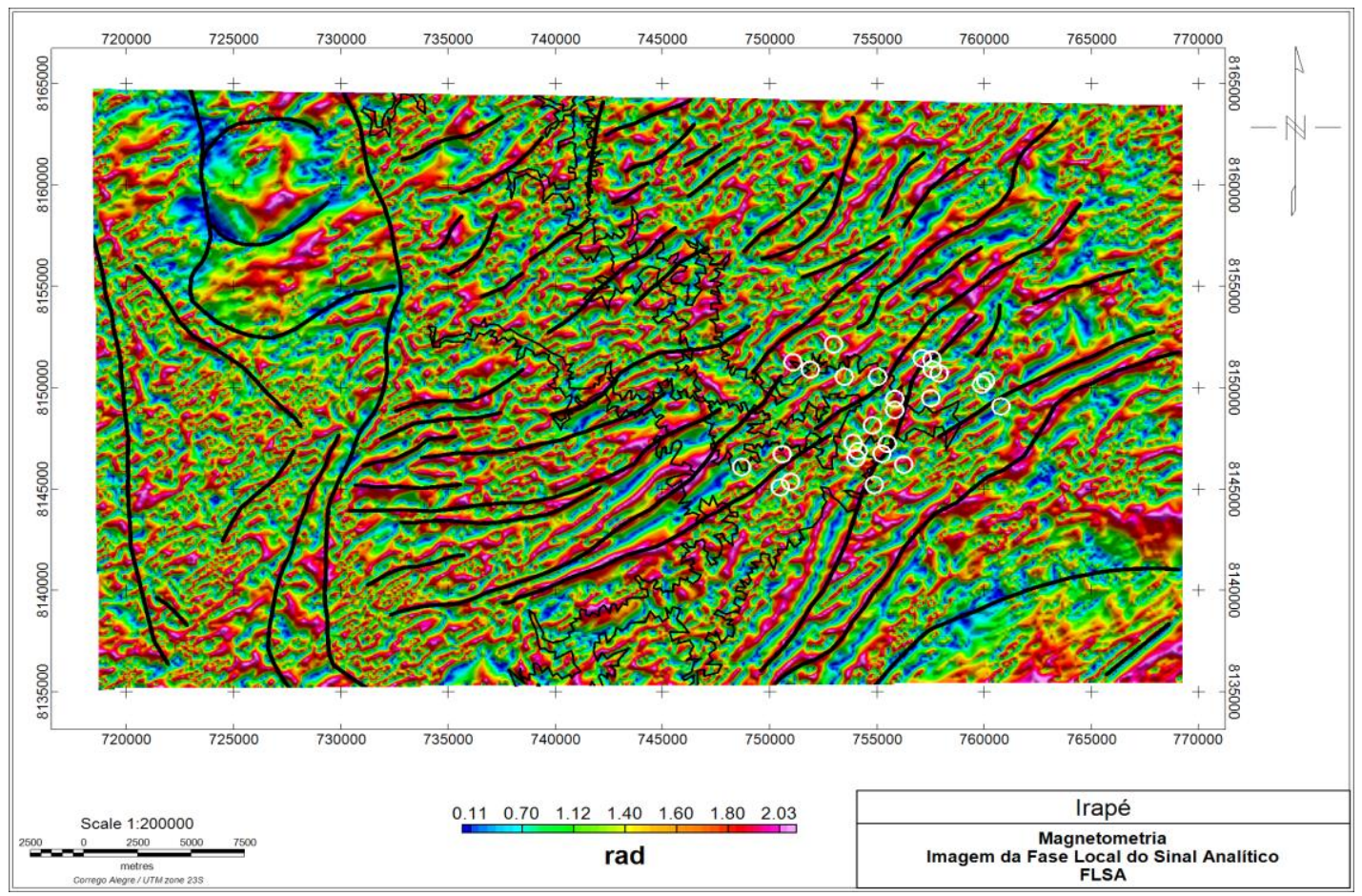

Figura 6 - Imagem FLSA com interpretação das estruturas magnéticas, contorno do reservatório de Irapé e os epicentros dos eventos sísmicos (círculos brancos).

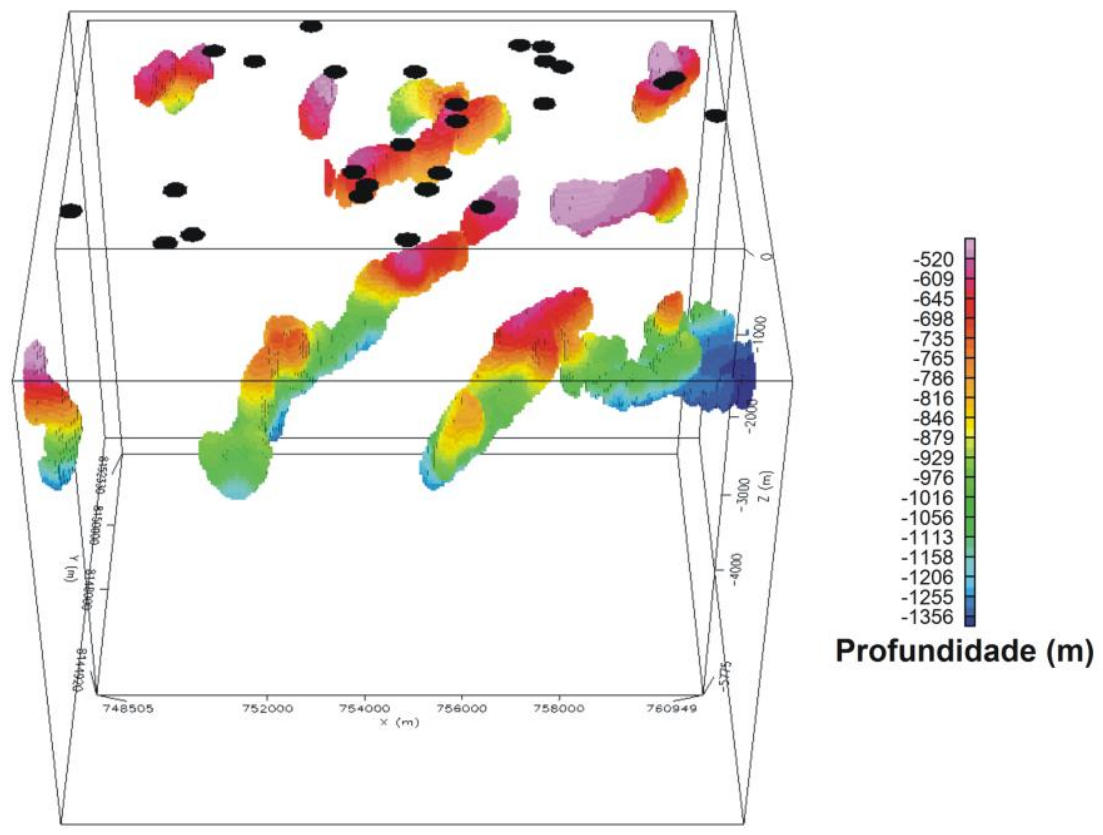

Figura 7 - Imagem 3D das estruturas magnéticas na área dos epicentros; vista de cima com ângulo de $\mathbf{3 0}$ graus. Notar a coincidência dos trends do sinal magnético e dos epicentros 
INTERPRET. CONJ. SISMIC. D. POR RESERV., E MAG. - IRAPÉ-MG.

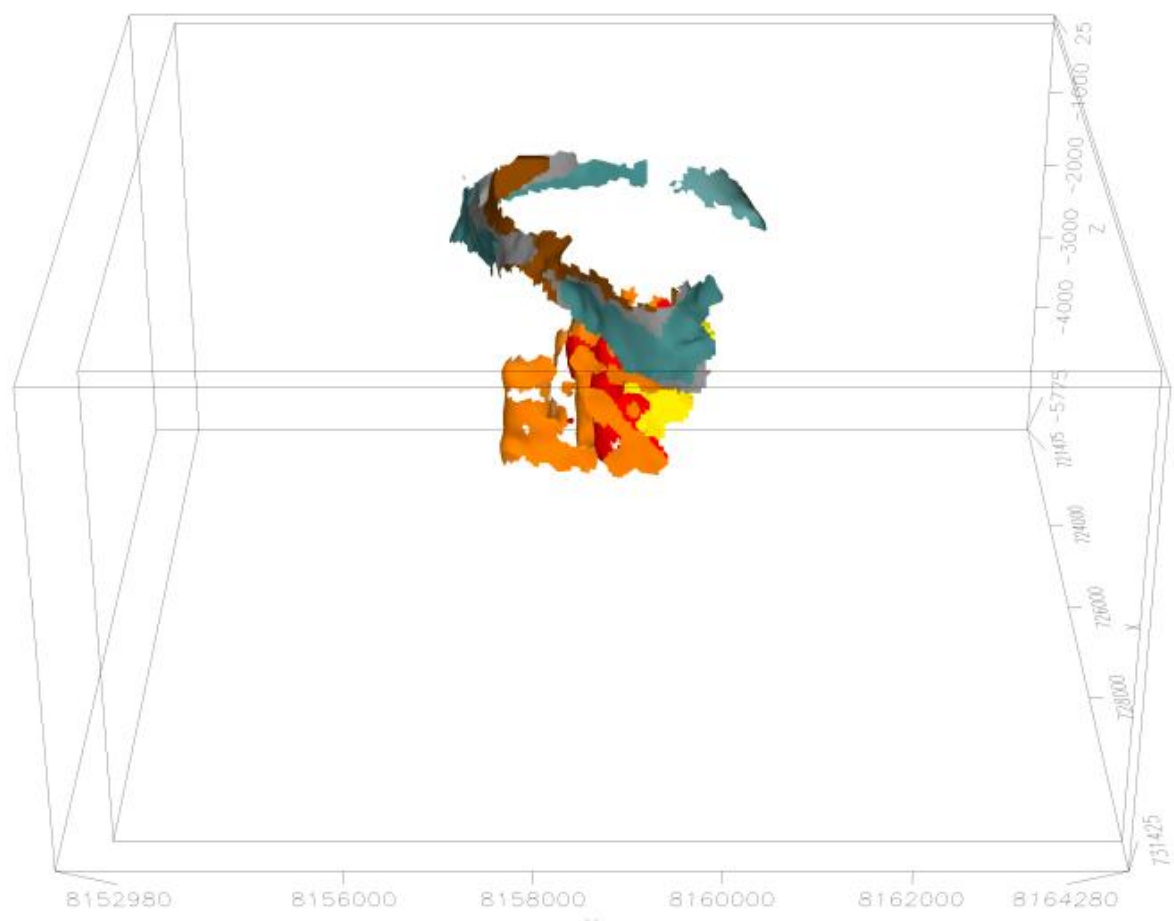

Figura 8 - Imagem 3D do corpo magnético (D4) com isosuperfícies magnéticas de baixa intensidade (azul), média intensidade (cinza e laranja) e alta intensidade (amarelo e vermelho); vista de leste para oeste. 